\title{
ACOMPANHAMENTO PSICOLÓGICO PREVENTIVO PARA AGENTES DE SEGURANÇA PÚBLICA
}

\author{
CAROLINE MOREIRA BACK
}

Psicóloga na Secretaria de Segurança Pública (GMSJP - PR); Especialização em Segurança Pública; Graduação em Psicologia (PUCPR); Cursando Graduação em Direito (FESPPR); Membro do Conselho Comunitário de Execuções Penais de São José dos Pinhais (CCEP-SJP).

País: Brasil Estado: Paraná Cidade: Curitiba

Email: cmback@gmail.comＯRCID: https://orcid.org/0000-0002-3723-1190

\section{RESUMO}

O presente estudo tem como propósito realizar uma análise crítica, visando compreender os riscos de adoecimento psíquico a que estão submetidos os profissionais de segurança, bem como as possibilidades de minimizar tais riscos a partir de ações preventivas. Foi possível concluir que o profissional que atua na segurança pública apresenta elevados riscos à saúde mental. Observou-se que entre os impactos mais significativos relatados pelos profissionais em sua atuação estão o risco de vida a que estão submetidos, a morte de colegas, as situações traumáticas e a necessidade de realizar atividades externas como complementação da renda. Quanto aos serviços de saúde mental nas instituições de segurança do país, observou-se que, além de não haver serviço de apoio psicológico em todas as instituições, naquelas em que este serviço existe, há diversas barreiras para o acesso dos profissionais, além de ações que priorizam situações de crise, não havendo atuação preventiva. Por fim, concluiu-se pela necessidade de ampliar o foco de atuação dos serviços existentes e criar estes serviços nos locais em que eles não existem, focando, sobretudo, em ações preventivas, como a oferta de apoio psicológico aos profissionais de segurança.

Palavras-chave: Segurança pública. Apoio psicológico. Prevenção. Saúde mental.

\section{ABSTRACT \\ PREVENTIVE PSYCHOLOGICAL SUPPORT FOR PUBLIC SECURITY AGENTS}

The present study is purpose perform a critical analysis, aiming to understand the risks of psychic illness to which the safety professionals are submitted, as well as the possibilities to minimize such risks of preventive actions. It was possible to conclude that the professional who works in public security presents high risks to mental health. It was observed that among the most significant impacts reported by professionals in their work are the risk of life to which they are subjected, the death of work partners, traumatic situations and the need to carry out external activities as a complement to income. As for mental health services in the country's security institutions, it was observed that in addition to the fact that there is no psychological support service in all institutions, in those where this service exists, there are several barriers for professionals to access, in addition to actions that prioritize crisis situations, with no preventive action. Finally, it was concluded that there was a need to expand the focus of existing services and create these services in places where they do not exist, focusing mainly on preventive actions, such as offering psychological support to security professionals.

Keywords: Public security. Psychological support. Prevention. Mental Health. 


\section{INTRODUÇÃO}

Sabe-se que a atuação na segurança pública demanda do agente grande responsabilidade inerente ao seu papel de promover segurança e bem-estar à população. Tal responsabilidade, aliada às demandas cotidianas de sua rotina de trabalho, o submete a uma constante exposição aos estressores que podem causar ou potencializar condições patológicas, tais como a ansiedade, os transtornos de humor, o uso abusivo de substâncias, entre outros.

A constante necessidade de alerta, visando manter-se em estado de prontidão para qualquer situação potencialmente ameaçadora à ordem pública, além da rígida disciplina e do necessário manejo de situações imprevistas decorrentes da atividade cotidiana de qualquer agente de segurança pública, seja policial civil ou militar, guarda municipal, agente penitenciário, entre outros, torna esses profissionais vulneráveis a transtornos relacionados ao estresse, como ansiedade, depressão, fobias, doenças psicossomáticas, alcoolismo e outras adições.

É preciso lembrar que existe o ser humano por trás da farda, que traz consigo toda uma carga de emoções e vivências pessoais, problemas cotidianos e familiares, dificuldades de ordem emocional e financeira, como qualquer outra pessoa. Desse profissional, no entanto, muitas vezes é exigida uma atuação em que características inerentes à condição humana são indesejáveis: é esperado que enfrente situações de perigo extremo e, diante disso, tenha autocontrole, não sinta medo, não se emocione, não demonstre fraqueza.

O trabalho na área de segurança pública é, portanto, um dos mais arriscados no que tange aos riscos para a saúde ocupacional, sendo esses profissionais expostos a condições que os colocam frente a riscos diários, numa condição limítrofe para o desenvolvimento de transtornos mentais.

Nesse sentido, se a atividade policial, por suas características intrínsecas, é fator de grande risco para o sofrimento psíquico do profissional, evidente que a preocupação com as suas condições de trabalho e com a sua saúde mental deve ser amplamente discutida. É preciso compreender que não basta ao agente de segurança apenas o preparo físico, técnico e tático; se não houver investimento e cuidado com seu preparo emocional, esse profissional não será capaz de desempenhar plenamente suas atividades.

Nesse sentido, justifica-se a relevância da produção de conhecimentos científicos sobre o tema, sobretudo com o intuito de compreender os riscos de adoecimento psíquico a que estão submetidos os profissionais de segurança e, além disso, explorar possibilidades de minimizar tais riscos a partir de ações preventivas, contribuindo de forma efetiva para o incremento da qualidade de vida dos agentes.

Assim, o objetivo deste estudo é propor uma reflexão crítica acerca do acompanhamento psicológico preventivo para agentes de segurança pública. Para tanto, buscou-se na literatura especializada referenciais teóricos sobre a relação entre a atuação na segurança pública e o sofrimento psíquico, estudos que abordam aspectos sobre a disponibilidade e o funcionamento de serviços de suporte psicológico em instituições de segurança pública do país, seus avanços e pontos críticos. 


\section{PROCEDIMENTOS METODOLÓGICOS}

Este estudo baseou-se em metodologia exploratória, do tipo pesquisa bibliográfica. Segundo Gil (2007), este método tem como objetivo proporcionar maior familiaridade com o problema, com vistas a tornálo mais explícito ou a construir hipóteses. A pesquisa bibliográfica é feita por meio do levantamento de referências teóricas já analisadas e publicadas por meios escritos e eletrônicos, como livros, artigos científicos e páginas de web sites, e permite a análise de diversas posições acerca de um problema. Nesse sentido, para Cervo, Bervian e Silva (2007, p. 61) é aquela pesquisa em que "se busca o domínio do estado da arte sobre determinado tema".

Assim, para atender aos objetivos propostos, foi realizada busca na literatura especializada visando reunir referenciais teóricos acerca da relação entre atuação na área de segurança pública e os riscos para a saúde mental dos agentes. A partir disso, buscaram-se artigos científicos resultantes de estudos que analisam essa relação, e também aqueles que tratam da disponibilidade e do funcionamento de serviços de atendimento e suporte psicológico em instituições de segurança pública do país, abarcando percepções dos profissionais envolvidos acerca da necessidade e dos efeitos dos serviços disponíveis, assim como das dificuldades percebidas. Os artigos foram selecionados em bases de dados disponíveis em meio eletrônico, prioritariamente Scientific Library Eletronic (Scielo); Periódicos Eletrônicos de Psicologia (PePSIC) e Google Scholar, sendo selecionados trabalhos relevantes e recentes, publicados entre os anos de 2010 e 2020.

Dessa forma, após ampla seleção dos artigos científicos, realizou-se uma leitura crítica e interpretativa, selecionando as publicações que apresentam a devida pertinência temática com o escopo deste estudo, correlacionando os achados e as descobertas das pesquisas com os referenciais teóricos utilizados. Por fim, os dados levantados foram descritos e analisados sob uma perspectiva crítica.

\section{SEGURANÇA PÚBLICA NO BRASIL}

Na Constituição Federal de 1988, em seu artigo 144, define-se a segurança pública como "dever do Estado, direito e responsabilidade de todos, exercida para a preservação da incolumidade das pessoas e do patrimônio" (BRASIL, 1988).

Em que pese sua expressa disposição legal, a garantia da segurança pública não se efetiva de forma simples, já que sua complexidade abarca outras questões além da integridade física dos sujeitos. A segurança não se define apenas por um estado físico mensurável, mas envolve o sentimento subjetivo de "estar seguro", associado à necessidade humana básica da fuga da dor (SALINEIRO, 2016).

De acordo com Souza e Albuquerque (2017), segurança pública em sua acepção coletiva tem o condão de resguardar tanto o Estado quanto os indivíduos e as instituições. Para a consecução de seus objetivos, o Estado articula o sistema institucional de segurança pública em seus diversos âmbitos, desde as ações de natureza policial, passando pelas jurídico-penais, judiciais ou de polícia penitenciária.

Para Costa (2010), tal organização pode ser entendida como um conjunto integrado e otimizado, composto por diversos instrumentos que envolvem coação, justiça, defesa dos direitos, de saúde e social. O autor defende que o processo de segurança pública começa em ações preventivas e tem seu término na reparação do dano, no tratamento das causas e na eventual reintegração à sociedade do autor do ilícito. 
A sociedade brasileira vive, entretanto, uma realidade difícil no âmbito da segurança pública. Segundo Costa (2010), as ameaças à segurança em razão do crescimento desordenado da violência estão relacionadas ao aumento da criminalidade, aos desequilíbrios social, racial e econômico, à falta de empregos, à marginalidade nos centros urbanos e aos processos migratórios.

Muito embora números absolutos não sejam capazes de representar as particularidades vivenciadas no dia a dia dos profissionais de segurança, pode-se ter uma ideia da amplitude da questão a partir dos dados que retratam a violência no Brasil. Em 2017, foram registrados 65.602 homicídios, o maior nível histórico de letalidade violenta intencional no país. Conforme o levantamento mais atual publicado no Anuário Brasileiro de Segurança Pública (FBSP, 2019), esse número caiu para 57.341 em 2018, o que representa uma redução de 10,80\% em relação ao ano anterior.

Porém, longe de ser motivo de comemoração, esses números ainda são muito preocupantes e alertam para os riscos da atividade policial em uma realidade violenta. Para além dos números, é preciso lembrar que os policiais são seres humanos enfrentando diariamente muitas das situações que culminam com as mortes violentas retratadas pelos dados. São eles que estão cotidianamente em situações de conflito armado, com riscos reais à vida e à integridade física, se envolvendo em situações de confronto que podem resultar em morte de ambas as partes. Só em 2018 foram 6.220 mortes violentas decorrentes de ações policiais. E não se pode esquecer que esses policiais são também vítimas da violência: em 2018, as mortes de policiais chegaram a 343 casos, sendo $75 \%$ fora de serviço (FBSP, 2019). Este dado aponta para a vivência de insegurança decorrente do trabalho policial, que não termina quando se encerra seu expediente.

Nesse sentido, em pesquisa que objetivou levantar características gerais acerca da letalidade e da vitimização policial em três Estados brasileiros, Zilli (2018) identificou fatores que predispõem os policiais a serem vítimas de morte violenta fora de seu expediente de trabalho, especialmente os fatos de portarem arma de fogo muitas vezes também nos horários de folga, realizarem "bicos" em atividades particulares de segurança quando não estão de serviço, e serem impelidos pela própria função a reagirem diante de ocorrências como assaltos, em defesa própria ou de terceiros, de maneira improvisada e sem apoio. Pelo fato de estarem portando arma de fogo, muitas vezes são atingidos pelas próprias armas que, uma vez identificadas pelos agressores, acabam sendo usadas contra os próprios agentes.

As consequências dessa sensação de estar sempre em risco e a percepção de condições de trabalho insatisfatórias podem ser gravíssimas. Em aprofundado estudo acerca do suicídio entre policiais militares do Rio de Janeiro, Miranda et al. (2016a) identificaram, dentre os participantes do estudo, que 100\% dos policiais que declararam atos suicidas também mencionaram vivências de situações de risco em suas atividades profissionais. Além disso, parte deles também mencionou ter participado de situações de confronto em que colegas foram alvejados e ter sofrido a perda de um colega e/ou amigo, por arma de fogo, em serviço, sugerindo correlação entre essas experiências e as tentativas de suicídio. O estudo ainda apontou associação entre o risco de suicídio aumentado e a insatisfação com recursos e material de trabalho, a falta de reconhecimento profissional na instituição, as poucas oportunidades de ascensão na carreira, a falta de apoio às equipes e a visão estigmatizada da atividade policial pela sociedade.

Nesse sentido, é pertinente a pontuação de Salineiro (2016), ao afirmar que o Brasil é um país inseguro, que conta com pouca efetividade no que tange aos esforços públicos na área de segurança e que provê condições precárias de trabalho aos seus agentes, que enfrentam as ruas com pouco treinamento e suporte e insuficientes recursos para o combate ao crime. 


\section{ATUAÇÃO NA SEGURANÇA PÚBLICA E IMPACTOS NA SAÚDE MENTAL}

Quando se fala em segurança pública, a saúde mental é um tema que precisa ser colocado em pauta. Dados da Organização Mundial da Saúde são preocupantes e apontam aumento no número de casos de depressão e transtornos de ansiedade no mundo e também no Brasil. O relatório mais recente acerca do tema, divulgado em 2017, indica que os casos de depressão aumentaram 18\% entre 2005 e 2015: são 322 milhões de pessoas em todo o mundo. No Brasil, a depressão atinge 11,5 milhões de pessoas, o que representa 5,80\% da população, enquanto distúrbios relacionados à ansiedade afetam mais de 18,6 milhões de brasileiros (WHO, 2017).

De acordo com dados solicitados às polícias civil e militar do Estado de São Paulo via Lei de Acesso à Informação, por meio da Ouvidoria dos referidos órgãos, entre 2015 e abril de 2020 houve um total de 12.622 afastamentos de policiais civis devido a "transtornos mentais e comportamentais", ou seja, afastados devido aos códigos constantes do capítulo $V$ do Manual de Classificação Internacional de Doenças (CID-10). A Polícia Militar divulgou seus dados em termos de porcentagem, indicando que, durante o período solicitado (2015 a 2020), 3,50\% do efetivo de Policiais Militares foram afastados do serviço devido a transtornos mentais e comportamentais.

Os números apresentados, embora devam ser considerados com cautela devido à diferença de metodologias de apuração e apresentação, indicam preocupação, pois evidenciam uma quantidade significativa de afastamentos nas maiores corporações policiais do país e, mais que isso, até mesmo a maneira de apresentar os dados sugere que tais afastamentos não são tratados com total transparência.

Essa questão é evidenciada no estudo de Martins e Lima (2018), que verificou a prevalência de transtornos mentais em policiais militares de Minas Gerais e sua relação com aspectos organizacionais, identificando que $50 \%$ dos profissionais em acompanhamento psicológico no serviço pesquisado evitava entrar em licença, pois este afastamento é visto pela instituição de forma negativa, como falta de comprometimento ou despreparo. Tais considerações revelam que os números de afastamentos por problemas mentais podem não representar a totalidade da incidência de tais transtornos nos profissionais de segurança, indicando uma realidade possivelmente ainda mais dramática.

Esse ponto traz à tona uma das grandes dificuldades em relação ao tema nas corporações, tendo em vista que causam preocupação não apenas os riscos psicossociais a que os profissionais estão submetidos, devido à própria atividade policial e consequente incidência significativa de transtornos mentais, mas também a maneira com que tais situações são tratadas, o que pode consistir em um fator de agravamento dos sintomas e das consequências decorrentes de tais transtornos, para o agente, seus familiares e a sociedade em geral.

Em resposta à preocupação causada por essas constatações, inúmeros estudos tentam lançar luz aos diversos aspectos relacionados a esse fenômeno. Autores como Anchieta; Galinkin; Mendes (2011); Minayo; Assis; Oliveira (2011); Castro (2012); Bezerra; Minayo; Constantino (2013); Pinto; Figueiredo; Souza (2013); Liz et al. (2014); Lima; Blank; Menegon (2015); Neves et al. (2016); Lima; Maia; Ferreira (2017); e Silva; Silva (2019) vêm apontando a relação entre a atuação na segurança pública e o desenvolvimento ou agravamento de transtornos mentais, abordando também em suas pesquisas os fatores relacionados e as estratégias de enfrentamento à questão. 
Nesse sentido, para Calazans (2010), muitos desses profissionais ingressam na carreira atraídos por status da profissão, possibilidades de ascensão e estabilidade do concurso público e, com o passar do tempo, acabam se deparando com a difícil realidade e, entre outros aspectos, com a falta de reconhecimento, a percepção do risco real e as perdas de colegas, gerando sofrimento mental.

Assim, vários estudos apontam altas prevalências de estresse, sofrimento psíquico e transtornos mentais e comportamentais entre agentes de segurança.

Neves et al. (2016) pesquisaram a incidência de estresse em policiais militares numa cidade do interior de Rondônia. Os resultados revelaram que $42 \%$ dos policiais participantes do estudo apresentavam sintomatologia de estresse na fase de resistência e $9 \%$ na fase de exaustão.

Outro estudo foi conduzido por Lima, Maia e Ferreira (2017), que pesquisaram a prevalência e os fatores associados aos transtornos mentais comuns em agentes de segurança penitenciária do sexo feminino, em cinco regiões brasileiras, em uma amostra de 295 participantes. Os resultados apontaram que cerca de $30 \%$ das entrevistadas apresentavam níveis compatíveis com transtornos mentais comuns.

Resultado semelhante foi encontrado por Pinto, Figueiredo e Souza (2013), ao pesquisarem o risco de adoecimento em policiais civis no Estado do Rio de Janeiro, tendo chegado a uma taxa de $21 \%$ dos participantes com indicativo de sofrimento psíquico. $O$ estudo ainda apontou correlação positiva entre a existência prévia de problemas de saúde relacionados ao sistema nervoso e a percepção de sofrimento psíquico por parte dos policiais.

Outro estudo que buscou inferir a prevalência de transtornos mentais relacionados à atuação na segurança pública foi o de Lima, Blank e Menegon (2015). Na pesquisa, os autores encontraram prevalência de $24 \%$ de causas relacionadas a transtornos mentais e comportamentais nos motivos de licença para tratamento de saúde dos policiais do Estado de Santa Catarina.

Em outra pesquisa, Bezerra, Minayo e Constantino (2013) avaliaram qualitativamente o estresse ocupacional em 42 mulheres policiais militares do Rio de Janeiro. Os resultados revelaram relação apontada pelas policiais entre o cotidiano de trabalho e o estresse. O sofrimento psíquico foi identificado mais fortemente entre as oficiais com cargos de chefia e as atividades operacionais foram consideradas as mais estressantes pelo risco que oferecem.

Conforme apontam outros estudos, um dos fatores preponderantes no desenvolvimento ou na piora dos quadros de sofrimento psíquico ou transtornos mentais que podem ser observados em agentes de segurança diz respeito aos riscos à vida e à necessidade de encarar a morte de seus pares.

Nesse sentido, Santiago e Souza (2016), ao analisarem o estresse laboral em Investigadores da Policia Civil nas delegacias da cidade de Manaus - AM, encontraram como resultado relevante, dentre outros, a percepção de que, para 94,12\% dos investigadores entrevistados, existe em suas atividades um constante risco à vida.

Pinto, Figueiredo e Souza (2013) ainda indicam, a partir do estudo realizado, que os riscos a que estão expostos os policiais, devido às suas atividades cotidianas, especialmente quando necessitam lidar com a morte ou a sua iminência, os colocam frente a um intenso sofrimento psíquico em sua relação com o trabalho. 
O estudo de Liz et al. (2014) comparou a percepção de estresse em uma amostra de 86 policiais militares de Florianópolis - SC, considerando suas características ocupacionais e sociodemográficas. Um dos resultados mais relevantes apontados pelo estudo indicou que os policiais que haviam sofrido algum evento traumático na carreira apresentavam níveis mais elevados de estresse quando comparados aos seus pares que não passaram por situações semelhantes.

Na mesma direção, o estudo conduzido por Gherson et al. (2009), citado por Liz et al. (2014), indicou a exposição a incidentes como um dos principais estressores em policiais, sendo os principais causadores de estresse: funerais de policiais, ser submetido à investigação de assuntos internos e atirar em alguém.

Outro ponto que merece atenção diz respeito ao trabalho em turnos de revezamento, adotado pelos profissionais de segurança pública. Essa rotina foi objeto de pesquisa em diversos estudos (Silva et al., 2010; Santos; Silva; Brasileiro, 2012; Arruda, 2014; Campos, 2014), os quais encontraram indicativos de que o trabalho nessa condição traz várias consequências negativas ao trabalhador, como distúrbios do sono, perturbações gastrointestinais e de humor, fadiga excessiva, hipertensão arterial, afetando aspectos biopsicossociais, familiares e interpessoais. Além disso, foi identificado que os trabalhadores que atuavam no turno da noite apresentavam maior prevalência de sofrimento psíquico, especialmente depressão, quando comparados àqueles que trabalhavam somente durante o dia.

Arroyo, Borges e Lourenção (2019) realizaram estudo com 506 policiais militares do Comando de Policiamento do Interior de São Paulo, no qual identificaram fatores relacionados ao trabalho policial com potencial de risco para sua saúde mental, sendo um dos principais a percepção de que os recursos financeiros recebidos são insuficientes, o que leva ao desenvolvimento de atividades informais, em dias alternados aos que o policial atua na corporação. Tal situação acaba comprometendo a realização de atividades de recreação e lazer, e potencializando o desgaste físico e mental dos profissionais.

Por fim, é pertinente citar o estudo de Lipp, Costa e Nunes (2017), que avaliaram os níveis de qualidade de vida e de estresse ocupacional e suas fontes em 1.837 policiais militares do Estado do Mato Grosso, encontrando um índice de 52\% destes que apresentavam estresse. Na conclusão, o estudo indicou urgência na implantação de ações que promovam aquisição de estratégias de enfrentamento ao estresse por parte dos agentes.

Em síntese, os impactos psicológicos relacionados à atuação em segurança pública descritos foram os seguintes:

- Estresse, associado ao cotidiano de trabalho e em decorrência de eventos traumáticos vivenciados na atuação profissional;

- Sofrimento psíquico e presença de transtornos mentais e comportamentais, relacionados a fatores como: falta de valorização profissional e de possibilidades de ascensão na carreira; risco iminente à vida; lidar com a morte de colegas; situações de investigação de conduta; necessidade de atirar em alguém; trabalho em turnos de revezamento, especialmente trabalho noturno (associado com prevalência de depressão); e necessidade de realizar trabalhos informais para complementar renda, resultando em ausência de momentos de lazer. 


\section{ESTRATÉGIAS DE PREVENÇÃO AO DESENVOLVIMENTO OU AGRAVAMENTO DE TRANSTORNOS MENTAIS}

Considerando que a segurança pública é uma das áreas mais arriscadas para o desenvolvimento de problemas de ordem mental e que os profissionais envolvidos nessa área são vítimas constantes de estresse ocupacional e pós-traumático, depressões e ideações suicidas (MINAYO, 2013), torna-se de grande relevância o desenvolvimento de estratégias de enfrentamento a essa situação.

Assim, vários são os estudos que buscam identificar meios para lidar com o problema, sendo que muitos deles sugerem a adoção de métodos preventivos para o enfrentamento do estresse inerente às profissões relacionadas à segurança pública, assim como para evitar o agravamento de condições desencadeadas pelo cotidiano da profissão (Dantas et al., 2010; Souza, 2011; Mendes, 2013; Elesbão, 2016; Neves et al., 2016; Pinheiro; Farikoski, 2016; Santiago; Souza, 2016).

Um desses estudos, realizado por Mendes (2013), aborda a saúde psicossocial na segurança pública brasileira, apontando como principal conclusão a importância da utilização, por parte das corporações, de métodos preventivos de alterações psicossociais. Para tanto, o autor sugere, dentre outras estratégias, a contratação de psicólogos para atuação em diversas áreas, realização de grupos de encontro para atendimento do público-alvo e que os atendimentos prestados fossem extensivos à família dos agentes, considerando as implicações do trabalho na segurança pública também aos familiares desses profissionais.

Em relação a esse ponto, é importante mencionar que os familiares dos agentes de segurança sofrem indiretamente as consequências do trabalho policial. O policial, em sua atuação, necessita mobilizar mecanismos psicológicos para enfrentar as diversas situações que a profissão exige diariamente (perigo constante, medo, morte e todos os demais fatores de estresse) e é inevitável que isso gere consequências. Nas relações familiares, tais consequências muitas vezes são evidenciadas, necessitando, por parte dos familiares, preparo para enfrentá-las conjuntamente ao policial. Nesse sentido, é importante considerar também esse apoio extensivo aos familiares dos agentes, como forma de auxiliá-los de maneira ampliada, contribuindo para um ambiente familiar mais saudável, fator de proteção ao desenvolvimento e agravamento de transtornos mentais.

Outro ponto relevante, apontado por Couto et al. (2012) em pesquisa com policiais militares, indica a importância da adoção de medidas para lidar com o estresse desde o início da carreira do agente, dando especial ênfase a esta fase, tanto quanto à percepção dos níveis de estresse quanto à qualidade das relações interpessoais, sugerindo que ações realizadas desde a formação dos profissionais tendem a capacitá-los preventivamente para o enfrentamento das situações futuras que precisarão enfrentar no cotidiano da profissão.

A esse respeito, vale mencionar que o início da carreira nas corporações conta com período específico destinado à formação dos futuros agentes. Nesse sentido, é importante que esses cursos de formação incluam formação específica e prática relacionadas ao âmbito psicológico do agente, tais como desenvolvimento de habilidades sociais, mecanismos de enfrentamento ao estresse, entre outras, preparando-os desde o início da carreira para o enfrentamento a tais situações e contribuindo preventivamente para a saúde mental dos profissionais.

Outro ponto importante foi mencionado por Elesbão (2016), que realizou um interessante estudo com policiais rodoviários do interior do Rio Grande do Sul, utilizando-se de grupos focais para abordar um tema 
recorrente no cotidiano desses profissionais: a morte. Segundo a autora, os momentos oportunizados pelo grupo facilitaram a reflexão sobre o tema e as discussões geradas permitiram perceber a importância de serem disponibilizados dispositivos de aproximação das instituições de segurança ao processo de escuta, promovendo, assim, reflexões acerca da morte e dos enfrentamentos diários vivenciados pelos profissionais de segurança em seu fazer profissional.

De fato, lidar com a finitude da vida é tarefa difícil para qualquer ser humano, porém, em profissões cujo fazer encontra-se diretamente relacionado à morte e ao morrer, tal tarefa se torna ainda mais difícil, sobretudo quando o enfrentamento à morte se dá de maneira tão direta. Nas profissões ligadas à segurança pública, a morte é um risco diário e a necessidade de encará-la cotidianamente mobiliza nos profissionais medos reais e profundos, sendo crucial a oportunização de espaços de escuta para auxiliar esses profissionais no enfrentamento da questão.

Outros estudos buscaram levantar propostas de atuação para o auxílio no desenvolvimento de ações efetivas de atenção à saúde mental nas corporações. Nesse sentido, Damaso et al. (2014) buscaram desenvolver propostas institucionais para prevenção e atenção aos riscos psicossociais no trabalho de policiais civis. A partir da pesquisa realizada, foi possível propor como estratégia o mapeamento dos riscos psicossociais por meio de instrumento específico e, a partir de tal diagnóstico, a criação de clínicas do trabalho como um meio de promoção, prevenção e atenção à saúde mental dos servidores policiais.

Outras formas mencionadas para o controle das emoções negativas e o gerenciamento do estresse, que podem ser promovidas por programas de atenção psicológica aos agentes de segurança, foram: acompanhamento psicológico individual (DANTAS et al., 2010), políticas institucionais antiestresse e acompanhamento psicológico (SOUZA, 2011); estratégias para a administração do tempo e incremento de habilidades sociais e, de um modo geral, melhora nas relações humanas (PELEGRINI; CALAIS; SALGADO, 2012).

Silva e Silva (2019) ainda apontaram para a importância de que esses profissionais contem com acompanhamento contínuo, com base em métodos preventivos de alterações psicossociais. Para os autores, os riscos inerentes às atividades ocupacionais dos profissionais de segurança não deixarão de existir, mas utilizando-se de ações preventivas é possível retardar e, até mesmo, eliminar as deteriorações física e mental que acometem esses profissionais.

Em síntese, as ações sugeridas nos estudos avaliados para a prevenção dos impactos psicológicos decorrentes da atuação na segurança incluem:

- Contratação de psicólogos onde não haja disponibilidade destes profissionais;

- Realização de grupos extensivos às famílias dos agentes, que também sofrem os impactos da atividade policial;

- Trabalhar estratégias de enfrentamento ao estresse desde o início da carreira, visando preparar o profissional para as situações que ele irá enfrentar no cotidiano de trabalho;

- Realização de intervenções em grupo para auxiliar os profissionais a lidarem com o tema morte;

- Mapeamento dos riscos psicossociais e realização de clínicas do trabalho; 
- Estratégias para administração do tempo e incremento de habilidades sociais;

- Acompanhamento psicológico individual, contínuo e preventivo.

\section{OFERTA DE ACOMPANHAMENTO PSICOLÓGICO NAS INSTITUIÇÕES DE SEGURANÇA PÚBLICA: REALIDADES E DESAFIOS}

Considerando as evidentes associações entre a atuação na segurança pública e o desenvolvimento e/ ou agravamento de transtornos mentais, além dos diversos estudos mencionados que apontam para a importância de ser ofertado aos agentes algum tipo de suporte psicológico frente a essas situações, resta verificar como isso vem ocorrendo na realidade das instituições de segurança do país, assim como as dificuldades percebidas e as perspectivas dessa atuação.

Inicialmente, cabe destacar que, a despeito da evidente necessidade, não são todos os órgãos de segurança que dispõem de serviços de atendimento psicológico para seus agentes. Exemplo disso é mencionado na publicação da Ouvidoria das Polícias de São Paulo acerca do suicídio policial (SÃO PAULO, 2019). O documento aponta taxas altíssimas de suicídio nas polícias do Estado mais populoso do país, verificadas entre os anos de 2017 e 2018 (21,70\% na Polícia Militar e 30,30\% na Polícia Civil), sendo a maior causa de vitimização policial, com taxas superiores aos homicídios e latrocínios. Mais que isso, mostra diferenças gritantes entre o tratamento das referidas instituições às questões de saúde mental de seus agentes. Enquanto a Polícia Militar conta com uma vasta rede de saúde, que possui diversos serviços e unidades de atendimento, incluindo um CAPS - Centro de Atenção Psicossocial e um NAPS - Núcleo de Atenção Psicossocial, a Polícia Civil do Estado sequer dispõe de serviço de atendimento psicológico para seus profissionais. A título de conclusão, a publicação ressalta a urgência na implantação desse serviço e na ampliação dos já existentes (SÃO PAULO, 2019).

Em relação aos serviços em funcionamento no país, destacam-se os estudos conduzidos por Castro (2012); Miranda et al. (2016b); Ferreira et al. (2017); Lustosa e Gonçalves (2017); e Martins e Lima (2018), que buscaram identificar nos serviços ofertados sua relevância, eficácia, limitações e sugestões de melhoria, na visão de pesquisadores, agentes de segurança e profissionais de saúde mental.

Castro (2012), em pesquisa acerca da prevalência de transtornos mentais e comportamentais (TMC) em policiais civis de Santa Catarina, apontou como um dado relevante o fato de que a maioria dos policiais afastados por TMC referiu-se à falta de apoio institucional quando de seu afastamento, ainda que a instituição conte com profissionais de psicologia em seu quadro. Esclarecimento da autora, que parece pertinente, é que a busca pelo atendimento, em sua maioria, é feita pelo próprio policial, não sendo um procedimento padrão da instituição diante da percepção de dificuldades apresentadas pelo profissional no trabalho.

Achado semelhante foi descrito por Bezerra (2013), que realizou um estudo qualitativo com policiais militares atuantes em Natal - RN acerca de cuidados com a saúde. No estudo foi reportada pelos agentes a cessação precoce do tratamento de saúde mental, devido às dificuldades de acesso aos profissionais de psicologia e psiquiatria da instituição e à impossibilidade de arcar com esse custeio por outros meios.

Essas situações parecem apontar para uma questão importante: não basta a existência de um serviço de psicologia na instituição, é preciso que o serviço seja disponível e facilmente acessado de maneira direta 
pelo agente, quando este sentir necessidade, mas também que esteja articulado com os demais setores da corporação como parte de uma estratégia institucional de proteção ao profissional.

Nesse sentido, é importante mencionar uma dificuldade que se infere dos estudos que envolvem saúde mental e segurança pública: a resistência dos agentes em buscarem apoio psicológico. Assim, se esse apoio fica restrito à busca espontânea pelo profissional, pode-se imaginar que não será plenamente efetivo, uma vez que muitos agentes não estarão dispostos a buscar ajuda espontaneamente.

Na mesma direção apontaram as conclusões de Bezerra, Minayo e Constantino (2016), em uma revisão de literatura acerca do sofrimento psíquico e do estresse no trabalho de agentes penitenciários. Os autores analisaram diversas publicações científicas sobre o tema, às quais indicaram como estratégias de enfrentamento ao problema itens como: formação, suporte social e atendimentos psicológicos. Os autores destacaram, porém, que os esforços para efetivação de tais estratégias não podem ser atribuídos apenas ao trabalhador, mas também devem ser considerados responsabilidade da instituição.

Ferreira et al. (2017), ao estudarem os riscos de adoecimento no trabalho em policiais militares de Brasília - DF, indicaram preocupações semelhantes. Segundo os autores, a rigidez do âmbito militar limita as possibilidades de comunicação direta e aberta, reforçando estratégias paralelas de comunicação entre os agentes, nas quais se fortalecem as racionalizações das situações de violência. Essa barreira na comunicação leva a uma maior resistência na busca de apoio emocional.

Miranda et al. (2016b), em amplo estudo acerca do comportamento suicida entre profissionais de segurança no Brasil, identificaram questões que se relacionam a essas dificuldades em estudos junto a policiais militares de três Estados brasileiros: Rio de Janeiro, Rio Grande do Sul e Bahia. Entre os achados do estudo que demonstraram dificuldades dos serviços existentes naqueles locais, destacamse: centralização dos serviços de apoio psicológico, sua pouca divulgação entre os profissionais, falta de confiança dos profissionais no serviço ofertado, visão estigmatizada do adoecimento mental dificultando a procura pelos serviços, e atuação com foco no problema já existente e não em estratégias de prevenção.

Com efeito, nota-se que quaisquer barreiras, sejam elas físicas (centralização ou mesmo ausência dos serviços de saúde mental), relacionadas à cultura institucional (visão estigmatizada por parte da instituição, falta de apoio ao profissional, dificuldades de comunicação), ou comportamentais (preconceitos, estigma da doença mental, desconfiança dos profissionais em relação à efetividade das intervenções, sigilo do profissional, entre outras), constituem grandes entraves na efetivação de políticas de atendimento e prevenção ao adoecimento mental na segurança pública.

Outro estudo que traz informações relevantes acerca de serviços de apoio psicológico nas corporações é o de Lustosa e Gonçalves (2017), os quais abordaram os desafios do serviço de psicologia da Polícia Militar de Minas Gerais. Os autores, que trouxeram um panorama do serviço a partir de sua prática profissional na instituição, alertaram para uma série de dificuldades que permeiam a concretização de um trabalho preventivo no âmbito de saúde mental dos agentes de segurança. Foram citados aspectos da cultura organizacional predominante na instituição militar, como as exigências rígidas e de cunho perfeccionista, a visão que considera o fracasso como inaceitável, entre outros pontos que levam a dificuldades para o sujeito colocar-se em posição de receber apoio emocional. Além disso, foi mencionado que ainda há o predomínio exclusivo da atividade clínica, devido à avaliação dos profissionais de saúde mental ser pautada exclusivamente em critérios quantitativos (número de atendimentos). Tal fator, segundo os autores, 
restringe a atuação do psicólogo, que poderia atuar em outros âmbitos da instituição, contribuindo, por exemplo, com as questões organizacionais que também levam ao adoecimento.

Importante notar que quaisquer estratégias de intervenção no âmbito da saúde mental e da segurança pública parecem apontar para uma maior efetividade quando consideram não apenas os fatores individuais relacionados ao sofrimento psíquico do agente, mas incluem estratégias que ampliam o foco de atenção para abarcar também aspectos ambientais, como uma melhora coletiva no ambiente de trabalho (MARTINS; LIMA, 2018), e se preocupam com a adesão de atores institucionais com papéis decisórios e também capacitações e orientações aos profissionais que estão à frente dos serviços de saúde mental (MIRANDA et al. 2016a).

Nota-se, assim, que as ações preventivas no âmbito da saúde mental dos agentes de segurança encontram dificuldades para sua efetivação que vão muito além da existência de um serviço estruturado para atendimento psicológico nas instituições, o que, por vezes, sequer existe. A complexidade inerente a essa discussão passa por fatores culturais, organizacionais, de oferta de recursos materiais, adesão de atores institucionais, entre outros fatores que precisam ser cada vez mais trazidos à tona, para serem discutidos, problematizados e que, assim, possam surgir propostas de intervenção mais efetivas e que contribuam para a construção de uma segurança pública mais atenta a seus agentes.

Em síntese, quanto aos serviços disponíveis em instituições de segurança, suas dificuldades, perspectivas e sugestões de melhoria, destacam-se:

- Não há disponibilidade de serviço de apoio psicológico em todas as instituições;

- Necessidade de busca externa por profissionais de psicologia e psiquiatria devido à sua ausência ou pouca disponibilidade na instituição;

- Falta de articulação entre o serviço ofertado e as demais políticas da instituição;

- Barreiras na comunicação e resistência dos profissionais em buscar os serviços;

- Serviços centralizados, distantes, pouco divulgados, e falta de confiança dos agentes nos profissionais de saúde mental;

- Foco nos problemas já existentes e ausência de estratégias preventivas;

- Aspectos da cultura organizacional das instituições de segurança, que dificultam a busca pelo atendimento psicológico;

- Necessidade de ampliar o foco de atuação para questões organizacionais e ambientais.

\section{CONSIDERAÇÕES FINAIS}

O presente estudo tem como objetivo propor uma reflexão crítica acerca do acompanhamento psicológico preventivo para agentes de segurança pública, a partir de achados decorrentes de estudos empíricos sobre o tema e sua correlação com as constatações presentes na literatura especializada. 
Assim, chegou-se à constatação inequívoca de que o profissional que atua na segurança pública encontrase sob alto risco de adoecimento psíquico, devido às pressões e exigências de seu fazer profissional, que inclui possibilidades reais de sofrer lesões e até mesmo perder a vida em proporções muito maiores do que a população em geral.

Em paralelo a isso, encontram-se as condições de trabalho em um ambiente rígido, hierarquizado, que impõe, muitas vezes, sobrecarga de trabalho e poucas oportunidades de relaxamento e lazer, uma vez que o policial encontra-se sempre em estado de prontidão, até mesmo em seus momentos de folga.

Assim, quando não se dá a devida atenção a essas questões, o que se vê são os altos índices de estresse e transtornos mentais, como ansiedade, depressão, doenças psicossomáticas e o abuso de substâncias cada vez mais prevalentes nesses profissionais, o que aponta para uma situação de extrema gravidade: além do sofrimento para si e para suas famílias, esses indivíduos necessitam portar armas de fogo para sua atuação profissional e, quando psicologicamente desequilibrados, isso pode resultar em consequências fatais para si e para terceiros.

Nos estudos analisados, foram identificados impactos psicológicos associados à atuação na segurança pública, sendo os mais prevalentes: o estresse associado ao fazer profissional e em decorrência de eventos traumáticos vivenciados no cotidiano de trabalho; e a presença de sofrimento psíquico e transtornos mentais e comportamentais. Tais impactos foram associados especialmente a fatores como o iminente risco à vida, inerente à atividade policial; a necessidade de lidar com a morte de colegas; a exposição a eventos traumáticos, como troca de tiros e investigações de conduta; o trabalho em turnos de revezamento, especialmente o trabalho noturno; e a realização de atividades externas como forma de complementação de renda.

Diversos estudos analisados ainda indicaram estratégias para minimizar esses impactos, sendo as principais: contratação de psicólogos em locais onde não há esse serviço disponível; realização de grupos para abordar temas como a morte, assunto este que aparece fortemente associado aos impactos negativos da atuação na segurança pública; realização de grupos extensivos às famílias dos agentes, pois elas também sofrem os impactos decorrentes da atividade policial; oferta de acompanhamento psicológico individual, contínuo e preventivo (não apenas diante de situações de crise); e estratégias que incluam administração do tempo e incremento de habilidades sociais.

Foram, ainda, identificados estudos que descreveram os serviços de saúde mental em instituições de segurança pública no país, suas práticas, seus resultados e desafios. Nesse sentido, os principais achados de tais estudos permitem concluir que, além de não haver serviço de apoio psicológico em todas as instituições, naquelas em que este serviço existe, há diversas barreiras para o acesso dos profissionais, tais como: falta de articulação com as políticas da instituição; pouca disponibilidade de profissionais; serviços centralizados e pouco divulgados; existência de barreiras na comunicação; resistência dos agentes em buscar apoio, devido a aspectos culturais presentes em organizações de segurança; além de ações que priorizam situações de crise, não havendo atuação preventiva.

Dos estudos realizados, surgiram também sugestões valiosas para o desenvolvimento de estratégias que possam atender de maneira mais ampla as necessidades dessas instituições e de seus agentes. Restou evidente a necessidade de ampliar o foco de atuação para abarcar questões de cultura organizacional, visando reduzir resistências, ampliar a busca pelos serviços de apoio psicológico e seu alcance, adotando- 
se também estratégias preventivas, pois a atuação em saúde mental pode e deve ir muito além do atendimento pontual em momentos de crise.

Nesse sentido, é preciso lembrar que o estresse e o adoecimento mental são, muitas vezes, naturalizados nas corporações, aspecto cultural arraigado e perpetuado em tais locais, dificultando o acesso dos agentes a serviços de acolhimento psicológico e mesmo a percepção dessa necessidade. Assim, nota-se que esses serviços precisam considerar tais dificuldades em seu fazer profissional, criando meios de contornar os problemas e superar as barreiras existentes, sendo que uma das formas que se vislumbra nesse sentido é a adoção de estratégias preventivas.

Quando se fala em prevenção, é preciso enfatizar que os serviços de apoio psicológico ofertados devem ir além da atuação quando o problema já está instalado e compreender uma série de ações que podem incluir desde a sensibilização dos profissionais e gestores quanto à importância dos cuidados em saúde mental, passando por estratégias de melhoria na comunicação e nas relações em geral, até a atuação em focos específicos, tais como na questão da morte, que foi um tema mencionado, em mais de um estudo, como algo potencialmente gerador de estresse e dificuldades para os agentes.

Assim, acredita-se que o apoio psicológico preventivo pode ser de grande relevância aos profissionais de segurança pública, contribuindo efetivamente para a melhoria de qualidade de vida, já que promove a saúde mental e previne o surgimento ou, ao menos, o agravamento de transtornos mentais nesses profissionais. Além disso, possibilita o suporte necessário diante das dificuldades que emergem do cotidiano da atuação profissional, o que, em última instância, contribui para a segurança da sociedade.

\section{REFERÊNCIAS BIBLIOGRÁFICAS}

ANCHIETA, Vania Cristine Cavalcanti; GALINKIN, Ana Lucia; MENDES, Ana Magnólia Bezerra. Trabalho e risco de adoecimento: um estudo entre policiais civis. Psicologia: Teoria e Pesquisa, Brasília-DF, v. 27, n. 2, p. 199-208, abr./jun. 2011. Disponível em: <http://www.scielo.br/pdf/ptp/v27n2/a07v27n2.pdf>. Acesso em: 1 fev. 2018.

ARROYO, Thiago Roberto; BORGES, Marcio Andrade; LOURENÇÃO, Luciano Garcia. Rev. Bras. Promoç. Saúde, v. 32, n. 7738, 2019. Disponível em: <https://periodicos.unifor.br/RBPS/article/view/7738/pdf>. Acesso em: 11 abr. 2019.

ARRUDA, Adenilda Teixeira. Trabalho noturno e sofrimento mental em trabalhadores da saúde de dois hospitais em Manaus, AM. 165p. Tese (Doutorado) - Escola Nacional de Saúde Pública Sergio Arouca, Rio de Janeiro - RJ, 2014. Disponível em: <https://www.arca.fiocruz.br/bitstream/icict/13141/1/177.pdf>. Acesso em: 3 fev. 2018.

BEZERRA, Adriana Karla de Oliveira Ferreira. Concepções de policiais militares sobre cuidados com a saúde. 110 p. Dissertação (Mestrado) - Universidade Federal do Rio Grande do Norte, Natal, 2013. Disponível em: <https://repositorio.ufrn.br/jspui/handle/123456789/14800>. Acesso em: 13 fev. 2019.

BEZERRA, Claudia de Magalhães; MINAYO, Maria Cecília de Souza; CONSTANTINO, Patrícia. Estresse ocupacional em mulheres policiais. Ciênc. Saúde Coletiva, Rio de Janeiro - RJ, v. 18, n. 3, mar. 2013. Disponível em: <http://www.scielo.br/pdf/csc/v18n3/11.pdf>. Acesso em: 28 jan. 2018.

BRASIL. Constituição da República Federativa do Brasil. Brasília - DF: Senado Federal: Centro Gráfico, 1988. 292 p. 
CALAZANS, Marcia Esteves. Missão prevenir e proteger: condições de vida, trabalho e saúde dos policiais militares do Rio de Janeiro. Cad. Saúde Pública, Rio de Janeiro - RJ, v. 26, n. 1, p. 206-211, jan. 2010. Disponivel em: <http://www.scielo.br/scielo.php?script=sci_arttext\&pid=S0102-311X2010000100022>. Acesso em: 5 fev. 2018.

CAMPOS, Íris Catarina Ventura. Consequências do Trabalho por Turnos. Dissertação (Mestrado) - Escola Superior de Ciências Empresariais da Escola Superior de Tecnologia, Instituto Politécnico Setúbal, Setúbal, 2014. Disponível em: <https://comum.rcaap.pt/bitstream/10400.26/8208/1/Disserta\%C3\%A7\%C3\%A3o_ Iris\%20Campos_120314006.pdf>. Acesso em: 4 fev. 2018.

CASTRO, Maria Cristina D`Avila de. Prevalência de transtornos mentais e comportamentais e percepção de suporte familiar em policiais civis. Dissertação (Mestrado) - Universidade Federal de Santa Catarina, Florianópolis - SC, 2012. Disponível em: <https://repositorio.ufsc.br/xmlui/bitstream/ handle/123456789/99345/305024.pdf?sequence=1\&isAllowed=y>. Acesso em: 29 jan. 2018.

CERVO, Amado; BERVIAN, Pedro Alcino; SILVA, Roberto da. Metodologia Científica. 6. ed. São Paulo: Pearson Prentice Hall, 2007.

COSTA, Marcos Antonio Cezar. Segurança Pública. Revista Núcleo de Criminologia. Paracatu - MG, n. 7, nov. 2010. Disponível em: <http://www.atenas.edu.br/uniatenas/assets/files/magazines/Revista_Nucleo_ Criminologia_07.pdf>. Acesso em: 5 fev. 2018.

COUTO, Gilmar; BRITO, Everton Araújo Garro; VASCONCELOS-SILVA, André; LUCCHESE, Roselma. Saúde mental do policial militar: relações interpessoais e estresse no exercício profissional. Rev. Psicol. Argum., Curitiba, v. 30, n. 68, p. 185-194, jan./mar. 2012. Disponível em: <https://periodicos.pucpr.br/index.php/ psicologiaargumento/article/view/20507/19761>. Acesso em: 4 fev. 2018.

DAMASO, Cristiane Ramos; GUIMARÃES, Dilma Dias; AVELAR, Inez Glória de Lima; SCALASSARA, Nadja Maria Nascimento Luna; VELOSO, Sônia América Marques. Práticas institucionais para prevenção e atenção aos riscos psicossociais no trabalho dos policiais civis do DF: contribuições da psicodinâmica do trabalho. TCC (Especialização) - Universidade de Brasília, Brasília, dez. 2014. Disponível em: <http:// www.bdm.unb.br/bitstream/10483/9781/1/2014_CristianeDamaso_DilmaGuimaraes\%20_InesAvelar_ NadjaScalassara_SoniaV.pdf>. Acesso em: 3 fev. 2018.

DANTAS, Marilza Aparecida; BRITO, Denilza Vitar Cantarino; RODRIGUES, Pâmela Batista; MACIENTE, Thiago Silvério. Avaliação de Estresse em Policiais Militares. Psicologia: Teoria e Prática, v. 12, n. 3, p. 66-77, mar. 2010. Disponível em:<http://pepsic.bvsalud.org/scielo.php?script=sci_arttext\&pid=S1516-36872010000300006>. Acesso em: 7 fev. 2018.

ELESBÃO, Cristiane Sperling. Um olhar sobre a presença da morte no cotidiano de trabalho dos policiais militares. 2016. 65 F. Dissertação (Mestrado) - Universidade Federal de Santa Maria, Santa Maria, 2016. Disponível em: <http://repositorio.ufsm.br/handle/1/10368?show=full>. Acesso em: 7 fev. 2018.

FBSP. FÓRUM BRASILEIRO DE SEGURANÇA PÚBLICA. Anuário Brasileiro de Segurança Pública 2019. 13. ed. 2019. Disponível em: <http://www.forumseguranca.org.br/wp-content/uploads/2019/10/Anuario2019-FINAL_21.10.19.pdf>. Acesso em: 28 abr. 2020.

FERREIRA, Leonardo Borges; SANTOS, Marcelo Augusto Finazzi; PAULA, Kesley Moraes de; MENDONÇA, Juliana Moro Bueno; CARNEIRO, Adailto Fernandes. Risco de adoecimento no trabalho: estudo com policiais militares de um batalhão de polícia de Brasília. Revista Gestão \& Sociedade, v. 11, n. 29, maio/ ago. 2017. Disponível em: <https://gestaoesociedade.org/gestaoesociedade/article/view/2150/1227>. Acesso em: 29 abr. 2020. 
GERSHON, R.R.M, BAROCAS, B., CANTON, A.N., LI, X., VLAHOV, D. Mental, physical, and behavioral outcomes associated with perceived work stress in police officers. Criminal justice and behavior. 2009;36(3):275-289. Disponível em: https://journals.sagepub.com/doi/abs/10.1177/0093854808330015. Acesso em: 31 jan. 2018.

GIL, Antonio Carlos. Como elaborar projetos de pesquisa. 4. ed. São Paulo: Atlas, 2007.

LIMA, Fabíola Polo de; BLANK, Vera Lúcia Guimarães; MENEGON, Fabrício Augusto. Prevalência de Transtorno Mental e Comportamental em Policiais Militares/SC em Licença para Tratamento de Saúde. Rev. Psicologia Ciência e Profissão, v. 3, n. 35, p. 824-840, 2015.

LIMA, Swelen Cristina Medeiros de; MAIA, Danilo Nogueira; FERREIRA, Marcelo José Monteiro. Prevalência e Fatores Associados aos Transtornos Mentais Comuns em Agentes de Segurança Penitenciária do Sexo Feminino no Brasil. Encontros Universitários da UFC, v. 2, n. 1, 2017.

LIPP, Marilda Novaes; COSTA, Keila Regina da Silva Nunes; NUNES, Vanessa Oliveira. Estresse, qualidade de vida e estressores ocupacionais de policiais: sintomas mais frequentes. Rev. Psicol. Organ. Trab., Brasília, v. 17, n. 1, p. 46-53, mar. 2017. Disponível em: <http://pepsic.bvsalud.org/scielo. php?script=sci_arttext\&pid=S1984-66572017000100006\&lng=pt\&nrm=iso >. Acesso em: 4 fev. 2018.

LIZ, Carla Maria; SILVA, Cirimbellida; ARAB, Leonardo; VIANA, Maike; BRANDT, Ricardo; VASCONCELOS, Itiberê Cunha; ANDRADE, Alexandro. Características ocupacionais e sociodemográficas relacionadas ao estresse percebido de policiais militares. Rev. Cubana de Medicina Militar, v. 4, n. 43, p. 467-480, 2014. Disponível em: <http://bvs.sld.cu/revistas/mil/vol43_4_14/mil07414.htm>. Acesso em: 31 jan. 2018.

LUSTOSA, Daniela Bizzotto Soares; GONÇALVES, Heli José. Psicologia na Polícia Militar: desafios no âmbito da cultura organizacional. Rev. Psicologia: Saúde Mental e Seg. Pública, Belo Horizonte, v. 3, n. 6, p. 3550, jan./jun. 2017.

MARTINS, Maria Cristina Garcia Costa; LIMA, Maria Elizabeth Antunes. Quando o policial procura ajuda psicológica: interfaces entre sofrimento e organização do trabalho. Rev. Psicologia: Saúde Mental e Seg. Pública, Belo Horizonte, 7, 43-64, jan./dez. 2018.

MENDES, Evaristo de Oliveira. A saúde psicossocial na segurança pública brasileira. TCC (Especialização) - Departamento de Estudos da Escola Superior de Guerra, Rio de Janeiro: ESG, 2013.

MINAYO, Maria Cecília de Souza. Condições de vida, saúde e trabalho dos profissionais de segurança pública. Rev. Ciênc. Saúde Coletiva, Rio de Janeiro, v. 18, n. 3, mar. 2013. Disponível em: <http://www. scielo.br/scielo.php?script=sci_arttext_pr\&pid=S1413-81232013010400001 >. Acesso em: 28 jan. 2018.

MINAYO, Maria Cecília de Souza; ASSIS, Simone Gonçalves; OLIVEIRA, Raquel Vasconcellos Carvalhães. Impacto das atividades profissionais na saúde física e mental dos policiais civis e militares do Rio de Janeiro - RJ, Brasil. Ciência \& Saúde Coletiva, v. 16, n. 4, p. 2199-2209, 2011. Disponível em: <http://www.scielo. br/pdf/csc/v16n4/v16n4a19.pdf>. Acesso em: 28 jan. 2018.

MIRANDA, Dayse et al. (Org.). Diagnóstico e prevenção do comportamento suicida na policia militar do Estado do Rio de Janeiro. 1. ed. Rio de Janeiro: Mórula Editorial, 2016a. 148 p. Disponível em: <http://gepesp.org/wp-content/uploads/2016/03/POR-QUE-POLICIAIS-SE-MATAM.pdf>. Acesso em: 27 abr. 2020. 
et al. O comportamento suicida entre profissionais de segurança pública e prevenção no Brasil. v. 6, Brasília: Ministério da Justiça e Cidadania, Secretaria Nacional de Segurança Pública, $2016 b$. [Col. Pensando a Segurança Pública]. Disponível em: <https://www.novo.justica.gov.br/sua-seguranca/ seguranca-publica/analise-e-pesquisa/download/estudos/pspvolume6/o_comportamento_suicida_ entre_profis_sp_prevencao_brasil.pdf>. Acesso em: 27 abr. 2020.

NEVES, Lídia; OLIVEIRA, Maria Letícia Marcondes Coelho de; FERREIRA, Daiane Fernandes; BATISTA, Eraldo Carlos. Sintomatologia de Estresse em Policiais Militares numa cidade do interior de Rondônia. Rev. Interd. do Pensamento Científico, v. 2, n. 14, jan./jun. 2016. Disponível em: <http://reinpec.srvroot. com:8686/reinpec/index.php/reinpec/article/view/163>. Acesso em: 31 jan. 2018.

PELLEGRINI, Carla Fernanda de Sousa; CALAIS, Sandra Leal; SALGADO, Manoel Henrique. Habilidades sociais e administração de tempo no manejo do estresse. Arq. Bras. Psicol., Rio de Janeiro, v. 64, n. 3, p. 110-129, dez. 2012. Disponível em: <http://pepsic.bvsalud.org/scielo.php?script=sci_arttext\&pid=S180952672012000300008\&lng=pt\&nrm=iso>. Acesso em: 1 fev. 2018.

PINHEIRO, Letícia Ribeiro Souto; FARIKOSKI, Camila. Avaliação do Nível de Estresse de Policiais Militares. Revista de Psicologia da IMED, Passo Fundo - RS, v. 8, n. 1, p. 14-19, ago. 2016, Disponível em: <https:// seer.imed.edu.br/index.php/revistapsico/article/view/1250>. Acesso em: 7 fev. 2018.

PINTO, Liana Wernersbach; FIGUEIREDO, Ana Elisa Bastos; SOUZA, Edinilsa Ramos. Sofrimento psíquico em policiais civis do Estado do Rio de Janeiro. Revista Ciência e Saúde Coletiva, v. 18, n. 3, p. 633-644, jun. 2013. Disponível em: <http://www.scielo.br/pdf/csc/v18n3/09.pdf>. Acesso em: 4 fev. 2018.

SALINEIRO, André. Políticas Públicas em Segurança Pública e Defesa Social. Curitiba: Intersaberes, 2016. SANTIAGO, Cirlene Bezerra. SOUZA, Julio Cesar Pinto de. Estresse ocupacional em investigadores da Polícia Civil de Manaus - AM. Revista Amazônica de Saúde - Revista Cientifica da Fametro - v. 2, n. 1, jul./nov 2016.

SANTOS, Claudenir Pereira; SILVA, Luciana Maria; BRASILEIRO, Marislei Espíndula. Alterações biopsicossociais relacionadas ao trabalho noturno. Rev. Eletr. de Enfermagem do Centro de Estudos de Enfermagem e Nutrição, v. 1, n. 1, p. 1-15, jan./jul. 2012. Disponível em: <http://www.ceen.com.br/ revistaeletronica>. Acesso em: 1 fev. 2018.

SÃO PAULO. Ouvidoria da Polícia do Estado de São Paulo. Uma análise crítica sobre o suicídio policial. 2019. Disponível em: <https://site.cfp.org.br/wp-content/uploads/2019/09/suicidio-policial_aprovacao_ mariano.pdf>. Acesso em: 29 abr. 2020.

SÃO PAULO. Serviço de Informação ao Cidadão da Polícia Militar do Estado de São Paulo - SIC/PM. Resposta à solicitação de informação. Solicitado em: 29 abr. 2020. Respondido em: 1 jun. 2020.

SÃO PAULO. Secretaria da Fazenda e Planejamento. Setor de Perícias Médicas do Estado de São Paulo. Resposta à solicitação de informação. Solicitado em: 29 abr. 2020. Respondido em: 19 maio 2020.

SILVA, Emerson Claudio Gonzaga; CHAFFIN, Rogério Azeredo; SILVA NETO, Vlado Cândido; SIQUEIRA JUNIOR, César Luis. Impactos gerados pelo trabalho em turnos. Perspectivas online, v. 4, n. 13. p. 6586, 2010. Disponível em: <http://www.seer.perspectivasonline.com.br/index.php/revista_antiga/article/ view/411>. Acesso em: 3 fev. 2018.

SILVA, Paulo Roberto Gonçalves; SILVA, Bruna Daniella de Souza. Profissional de Segurança Pública: do tratamento moral à atenção psicossocial. TCC (Especialização) - Programa de Formação de Praças do Comando da Academia da Polícia Militar de Goiás, Goiás, 2019. Disponível em: <https://acervodigital.ssp. go.gov.br/pmgo/handle/123456789/1752>. Acesso em: 2 maio 2019. 
SOUZA, Cézar Alberto; ALBUQUERQUE, Marinson Luiz. Segurança Pública: histórico, realidade e desafios. Curitiba: Intersaberes: 2017.

SOUZA, Mario Luiz Pinheiro. Stress Policial na PMMT: Uma análise das causas, consequências e políticas de intervenção. RHM - Revista Científica de Pesquisa em Segurança Pública, v. 7, jul./dez. 2011. Disponível em: <http://revistacientifica.pm.mt.gov.br/ojs/index.php/semanal/article/view/175/pdf_72>. Acesso em: 31 jan. 2018.

WHO. World Health Organization. Depression and other common mental disorders. Global Health Estimates, 2017. Disponível em: <https://apps.who.int/iris/bitstream/handle/10665/254610/WHO-MSDMER-2017.2-eng.pdF;jsessionid=A1EF7626C774D07770393972476F88C9? sequence=1>. Acesso em: 27 abr. 2020.

ZILLI, Luis Felipe. Letalidade e Vitimização Policial: Características Gerais do Fenômeno em três estados brasileiros. Boletim de Análise Político-Institucional, n. 17, dez. 2018. Disponível em: <http://repositorio. ipea.gov.br/bitstream/11058/8873/1/bapi_17_cap_10.pdf>. Acesso em: 30 abr. 2020.
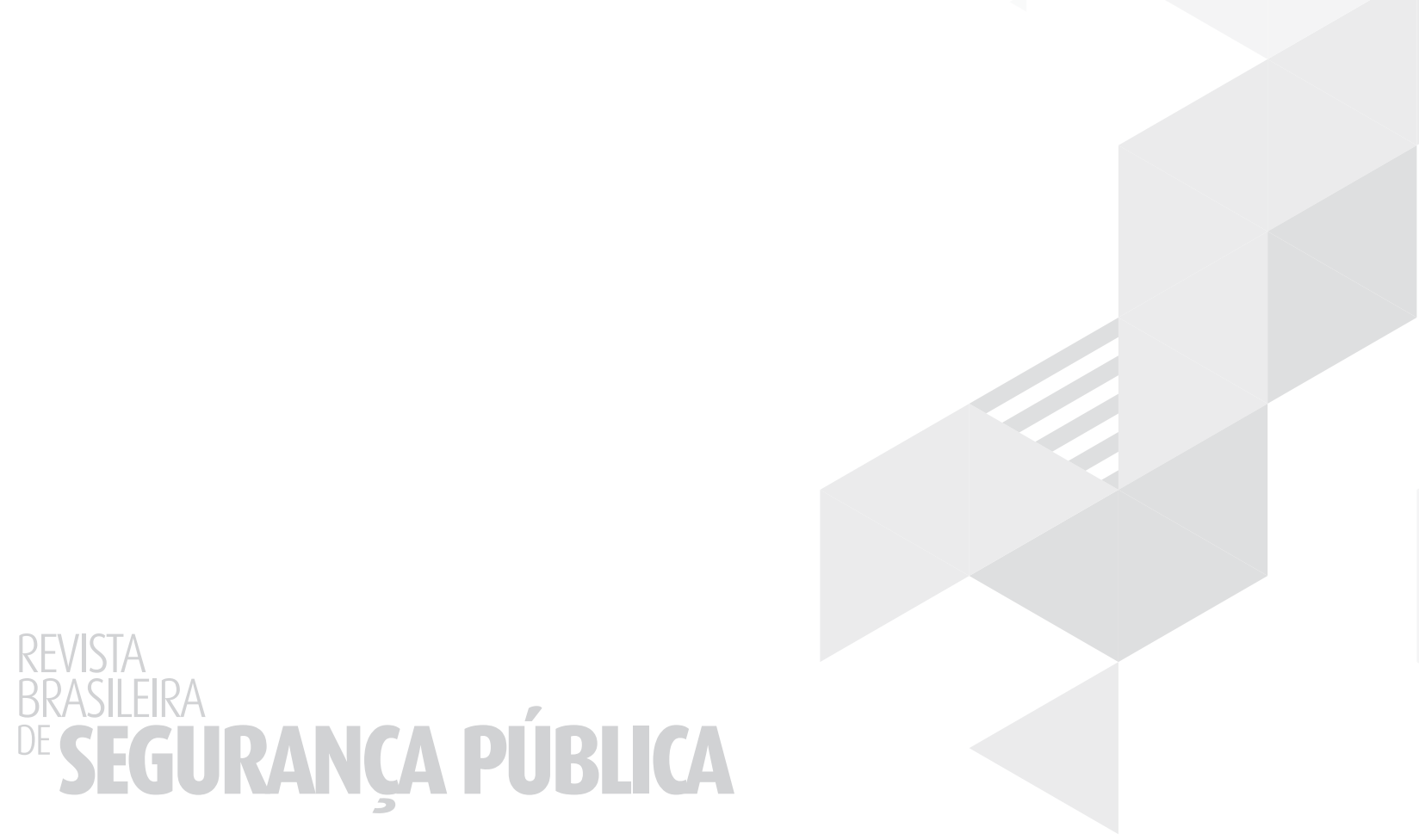